\title{
Managing dyspnea in patients with advanced chronic obstructive pulmonary disease: A Canadian Thoracic Society clinical practice guideline
}

\author{
Darcy D Marciniuk MD FRCPC FCCP ${ }^{*}$, Donna Goodridge RN PhD ${ }^{1}$, Paul Hernandez MDCM FRCPC ${ }^{2 *}$, \\ Graeme Rocker MHSc DM FRCPC FCCP ${ }^{2}$, Meyer Balter MD FRCPC FCCP ${ }^{3}$, Pat Bailey RN PhD ${ }^{4}$, \\ Gordon Ford MD FRCPC ${ }^{5 *}$, Jean Bourbeau MD MS, FRCPC ${ }^{*}$, Denis E O'Donnell MD FRCPI FRCPC ${ }^{7 *}$, \\ Francois Maltais MD FRCPC ${ }^{8 *}$, Richard A Mularski MD MSHS MCR FCCP9†, Andrew J Cave MB ChB FCFP10†, \\ Irvin Mayers MD FRCPC ${ }^{10 \dagger}$, Vicki Kennedy RN BN CRE ${ }^{11}$, Thomas K Oliver BA ${ }^{12,13}$, Candice Brown MSc CEP ${ }^{12}$; \\ Canadian Thoracic Society COPD Committee Dyspnea Expert Working Group
}

\begin{abstract}
DD Marciniuk, D Goodridge, P Hernandez, et al; Canadian Thoracic Society COPD Committee Dyspnea Expert Working Group. Managing dyspnea in patients with advanced chronic obstructive pulmonary disease: A Canadian Thoracic Society clinical practice guideline. Can Respir J 2011;18(2):69-78.
\end{abstract}

Dyspnea is a cardinal symptom of chronic obstructive pulmonary disease (COPD), and its severity and magnitude increases as the disease progresses, leading to significant disability and a negative effect on quality of life. Refractory dyspnea is a common and difficult symptom to treat in patients with advanced COPD. There are many questions concerning optimal management and, specifically, whether various therapies are effective in this setting. The present document was compiled to address these important clinical issues using an evidence-based systematic review process led by a representative interprofessional panel of experts.

The evidence supports the benefits of oral opioids, neuromuscular electrical stimulation, chest wall vibration, walking aids and pursed-lip breathing in the management of dyspnea in the individual patient with advanced COPD. Oxygen is recommended for COPD patients with resting hypoxemia, but its use for the targeted management of dyspnea in this setting should be reserved for patients who receive symptomatic benefit. There is insufficient evidence to support the routine use of anxiolytic medications, nebulized opioids, acupuncture, acupressure, distractive auditory stimuli (music), relaxation, handheld fans, counselling programs or psychotherapy. There is also no evidence to support the use of supplemental oxygen to reduce dyspnea in nonhypoxemic patients with advanced COPD.

Recognizing the current unfamiliarity with prescribing and dosing of opioid therapy in this setting, a potential approach for their use is illustrated. The role of opioid and other effective therapies in the comprehensive management of refractory dyspnea in patients with advanced COPD is discussed.

Key Words: Chronic obstructive pulmonary disease; COPD; Dyspnea; Management

$\mathrm{D}$ spnea is the subjective experience - usually unpleasant - of discomfort with breathing (1). Dyspnea is a cardinal symptom of chronic obstructive pulmonary disease (COPD), and its severity and magnitude increases as the underlying disease progresses, leading to significant disability. For patients with advanced COPD, dyspnea profoundly affects quality of life ( $\mathrm{QoL}$ ) to the extent that patients become isolated, often describing themselves as 'existing' rather than 'living' (1). Patients with advanced COPD almost universally experience significant dyspnea in the final year of life (2). Moreover, COPD patients at the end of life experience more dyspnea than lung cancer patients (2) and, yet, are often prescribed less medication and have less access to comprehensive care than patients dying from lung cancer $(3,4)$.
La prise en charge de la dyspnée chez les patients atteints de maladie pulmonaire obstructive chronique avancée : des directives cliniques de la Société canadienne de thoracologie

La dyspnée est un symptôme cardinal de maladie pulmonaire obstructive chronique (MPOC). Sa gravité et son importance s'accroissent à mesure que progresse la maladie, entraînant une invalidité marquée et un effet négatif sur la qualité de vie. La dyspnée réfractaire est un symptôme courant et difficile à traiter chez les patients atteints de MPOC avancée. De nombreuses questions se posent quant à sa prise en charge optimale, notamment si diverses thérapies sont efficaces dans un tel contexte. Le présent document a été compilé pour répondre à ces questions cliniques importantes au moyen d'un processus systématique probant dirigé par un groupe représentatif d'experts interprofessionnels.

Les données probantes appuient les bienfaits des opioïdes par voie orale, de la stimulation neuromusculaire électrique, de la vibration de la paroi de la cage thoracique, des aides à la marche et de la respiration les lèvres pincées pour prendre en charge la dyspnée chez un patient ayant une MPOC avancée. L'oxygène est recommandé chez les patients atteints de MPOC qui font de l'hypoxémie au repos, mais son utilisation pour la prise en charge ciblée de la dyspnée devrait être réservée aux patients qui en tirent des bienfaits symptomatiques. On ne possède pas assez de données probantes pour étayer l'utilisation systématique des anxiolytiques, des opioïdes par nébulisation, de l'acupuncture, de l'acupression, du stimulus sonore distractif (musique), de la relaxation, deséventails, des programmes de counseling ou de la psychothérapie. Par ailleurs, on ne possède pas de données probantes pour appuyer l'utilisation de suppléments d'oxygène pour réduire la dyspnée chez les patients non hypoxémiques ayant une MPOC avancée.

Compte tenu du peu de connaissances actuelles sur la prescription et la posologie des traitements aux opioïdes dans cette situation, on expose une démarche potentielle relativement à leur utilisation. Le rôle des opioïdes et d'autres thérapies efficaces pour la prise en charge complète de la dyspnée réfractaire chez les patients ayant une MPOC avancée est présenté.

The prevention, relief, reduction and soothing of dyspnea symptoms - without affecting a cure - should be an integral component of standard care for COPD. The optimal management of dyspnea in patients with advanced COPD is, however, an often neglected aspect in the continuum of care $(5,6)$. In a recent Canadian multicentre study (7), relief of symptoms such as dyspnea was a top priority targeted for improvement in the care provided to patients hospitalized with COPD.

Dyspnea is a complex symptom arising from the interaction and dependence of various signals and processes including an individual's reactions and perceptions. The present document is not intended to review or explore the mechanisms of dyspnea in this setting - readers are advised to consult appropriate reference material (8-10).

${ }^{1}$ University of Saskatchewan, Saskatoon, Saskatchewan; ${ }^{2}$ Dalhousie University, Halifax, Nova Scotia; ${ }^{3}$ University of Toronto, Toronto; ${ }^{4}$ Laurentian University, Sudbury, Ontario; ${ }^{5}$ University of Calgary, Calgary, Alberta; ${ }^{6} \mathrm{McGill}$ University, Montreal, Quebec; 7 Queen's University, Kingston, Ontario; ${ }^{8}$ Laval University, Laval, Quebec; ${ }^{9}$ Kaiser Permanente Northwest, Oregon/Washington, USA; ${ }^{10}$ University of Alberta, Edmonton, Alberta;

${ }^{11}$ Saskatoon Health Region, Saskatoon, Saskatchewan; ${ }^{12}$ Canadian Thoracic Society, Ottawa; ${ }^{13}$ McMaster University, Hamilton, Ontario.

*Canadian Thoracic Society COPD Executive Committee Member; ${ }^{\dagger}$ Expert reviewer

Correspondence: Dr Darcy Marciniuk, Chair, Canadian Thoracic Society COPD Committee, 300-1750 Courtwood Crescent, Ottawa, Ontario K2C 2B5. Telephone 613-569-6411, fax 613-569-8860, e-mail ctsinfo@lung.ca

Request for reprints: Canadian Thoracic Society, 300-1750 Courtwood Crescent, Ottawa, Ontario K2C 2B5. Telephone 613-569-6411,

fax 613-569-8860, e-mail ctsinfo@lung.ca 
TABLE 1

Strength of evidence and grading of recommendations Quality of evidence

Grade A

Well-designed randomized controlled trials with consistent and directly applicable results

Grade B

Randomized trials with limitations including inconsistent results or major methodological weaknesses

Grade C

Observational studies, and from generalization from randomized trials in one group of patients to a different group of patients

Strength of recommendations

Grade 11 Strong recommendation, with desirable effects
clearly outweighing undesirable effects (or
vice versa)

Grade $2 \quad$ Weak recommendation, with desirable effects closely balanced with undesirable effects

Adapted from references 13 and 15

The present guideline statement presupposes that appropriate pharmacological therapies including short- and long-acting bronchodilator therapies, inhaled corticosteroids in combination with long-acting beta-2 agonists, theophylline preparations and nonpharmacological therapies including pulmonary rehabilitation, have been and continue to be optimally used in the management of dyspnea for patients with advanced COPD.

There remain many questions, clinical care gaps and treatment barriers regarding the optimal management of dyspnea in patients with advanced COPD and, specifically, whether various therapeutic options are effective in this setting. The current document is intended to specifically address these important clinical issues, using an evidencebased systematic review process led by a representative interprofessional panel of experts in the field.

\section{Target population}

The present clinical practice guideline provides direction on managing dyspnea in patients with advanced COPD. For the purposes of the present guideline, patients with advanced COPD are defined as those with COPD associated with either a forced expiratory volume in $1 \mathrm{~s}$ of lower than $50 \%$ predicted, or a medical research council dyspnea score of 4 to 5 in the setting of progressive disease associated with a limited prognosis. The specific management goal is to reduce persistent dyspnea that is distressing at rest or with minimal activity despite optimal therapy of advanced lung disease (11).

\section{Target users}

The current document is intended for all health care professionals involved in the care of patients experiencing dyspnea associated with advanced COPD including respirologists, family physicians, internists, nurses and health care administrators.

\section{Methodology}

Guideline development process: The Canadian Thoracic Society (CTS) clinical practice guideline document on managing dyspnea in patients with advanced COPD was developed by an expert working group panel of representative professionals involved in the care of patients with advanced COPD. Membership included respirologists, family physicians, internists, nurses and health care administrators. The overall process was coordinated by the CTS Respiratory Guideline Committee and staff, with the assistance of a consultant librarian and methodology experts. The guideline was developed in accordance with the convention of the 23-item Appraisal of Guidelines for Research and Evaluation (AGREE) II instrument (12) - the current gold standard in appraising the reporting of clinical practice guidelines. The research questions were prepared based on the working group's recognition of clinical care gaps and the solicited needs of the target populations. Questions were constructed in accordance with a 'PICO' process, taking into consideration the Problem, Intervention, Comparison and Outcomes within each research question, thus ensuring that an appropriate and answerable question was constructed. This process also enabled the development of a literature search strategy that outlined the types of studies, main topics and terms, inclusion and exclusion criteria, as well as suitable databases in which to conduct the search. The strength of evidence was assessed and recommendations were graded as outlined in Table 1.

\section{Literature search}

Based on the criteria outlined in the search strategy for each of the research questions, MEDLINE, EMBASE, the Cochrane Library, the Canadian Medical Association InfoBase and the National Guideline Clearinghouse were searched for pertinent published literature between January 1996 and March 2009. In addition, supplementary references of selected papers and recent review articles were also scanned by the expert working group members for additional citations.

\section{Evidence selection}

An initial review of abstracts was performed to inform selection of articles for which the full text was required, with a minimum of two working group members assigned to each research question. Once full-text articles were retrieved, data extraction tables were used to systematically extract evidence from the included/relevant full-text articles based on the predetermined inclusion and exclusion criteria supporting the research question (Table 2). These tables were used to summarize and organize information (ie, study design, target population, interventions, outcomes, and functional and clinical significance of findings) for the formulation of recommendations and supporting narrative text. Complete data extraction tables are available as online supplemental material (www.respiratoryguidelines.ca/guideline/chronic-obstructivepulmonary-disease or www.pulsus.com). Articles were evaluated for the following outcomes: reduction in dyspnea, improved exercise capacity, improved activity, improved QoL/health status, decreased exacerbations, decreased health care use and cost effectiveness. Narrative text of key evidence and conclusions supporting the recommendations were completed based on the data extracted.

\section{Formulating recommendations}

Decisions regarding the strength of recommendations were achieved through a formal consensus process whereby working group members assigned to each of the research questions considered the strength of the evidence using the Grades of Recommendation, Assessment, Development and Evaluation (GRADE) methodology (13). In addition, adverse effects, health benefits to patients, the burden on the patient associated with adherence to the recommendations, extent to which the evidence directly addresses the research question, and impact on morbidity, mortality and QoL were considered $(13,14)$ by the expert working group members. Final consensus on the recommendations by the full committee was achieved via an open voting process. Extensive discussions were held to edit, correct and update the document.

\section{External expert commentary and review}

Expert reviewers identified by the working group and the Canadian Respiratory Guidelines Committee, on the basis of their clinical and methodological expertise, were invited to review the document. A draft of the clinical practice guidelines was circulated to the reviewers, feedback was gathered and relevant changes were incorporated into the document. Reviewers also used a short AGREE II (12) checklist to document their appraisal and enhance the usability of the document.

The present document, including the questions and content, will be regularly reviewed and updated to reflect the changing and growing body of evidence in this area. At minimum, after a two-year period, the literature will be reviewed for new evidence to further inform, revise or update the guideline recommendations. 
TABLE 2

Literature search results informing recommendations

\begin{tabular}{|c|c|c|}
\hline Section & Topic & $\begin{array}{l}\text { Studies informing recommendations } \\
\text { for practice, } \mathrm{n} \text { (references) }\end{array}$ \\
\hline I & $\begin{array}{l}\text { Do anxiolytic and antidepressant medications reduce dyspnea and improve quality of life in stable } \\
\text { patients with advanced COPD compared with usual care (control population)? }\end{array}$ & $13(18-30)$ \\
\hline II & $\begin{array}{l}\text { Do opioids reduce dyspnea and improve quality of life in stable patients with advanced COPD when } \\
\text { used as an adjunct to optimal conventional treatment? }\end{array}$ & $10(34-43)$ \\
\hline III & $\begin{array}{l}\text { Do nonpharmacological interventions (use of a fan, chest vibration techniques, pursed-lip breathing, } \\
\text { meditation, relaxation therapy or behavioral techniques) reduce dyspnea and improve quality of life in } \\
\text { stable patients with advanced COPD compared with usual care (control population)? }\end{array}$ & 38 (45-82) \\
\hline IV & $\begin{array}{l}\text { Does supplemental oxygen reduce dyspnea and improve quality of life in stable patients with advanced } \\
\text { COPD compared with usual care (control population) in patients with hypoxemia, and in patients } \\
\text { without hypoxemia? }\end{array}$ & $12(93-104)$ \\
\hline
\end{tabular}

COPD Chronic obstructive pulmonary disease

\section{SECTION I}

\section{Question}

Do anxiolytic and antidepressant medications reduce dyspnea and improve QoL in stable patients with advanced COPD compared with usual care (control population)?

\section{Introduction}

Anxiety, panic and depression are psychological disturbances common in patients with COPD. Depending on the screening methodology used and the population studied, prevalence ranges from 10\% to $33 \%$ for generalized anxiety, $0 \%$ to $70 \%$ for panic attacks and $10 \%$ to $40 \%$ for depression $(16,17)$. Dyspnea is a complex symptom that evokes strong emotional reactions of fear, distress, anxiety and panic (8). Conversely, affective state can modulate respiratory sensory thresholds and, therefore, exacerbate the perception of dyspnea (8). Measures of anxiety and depression correlate with impaired health-related $\mathrm{QoL}$ (HRQoL), physical and social functioning, and mortality in patients with COPD $(16,17)$. It has been postulated that nonpharmacological and pharmacological strategies to treat anxiety and depression may be helpful in relieving dyspnea and improving HRQoL in patients with COPD. This section evaluates the evidence regarding medications with anxiolytic properties that reduce dyspnea and improve $\mathrm{QoL}$ in patients with advanced COPD.

\section{Key evidence}

A total of 106 abstracts were initially identified by the search process, of which 43 were selected for complete review. Thirteen studies fully met the criteria and were selected for data extraction and utilization.

Four studies (18-21) investigating the role of benzodiazepine-class (alprazolam in two, diazepam in two) anxiolytic medications in moderate to severe COPD were identified. Three studies were short-term (a few weeks), randomized, placebo-controlled, crossover trials in a small number of subjects ( $n=4$ to $n=29$ ), while one article was a case report. There were conflicting results reported for relief of dyspnea. The largest study (20 [n=29]) compared alprazolam $0.5 \mathrm{mg}$ twice daily with placebo. There was no change in chronic dyspnea (medical research council score), exercise-related dyspnea or distance travelled in a $12 \mathrm{~min}$ walk test (12MWT). Drowsiness was the most common side effect reported in the studies, although in general, benzodiazepines were well tolerated.

Buspirone is a serotinergic, anxiolytic medication used in the short-term treatment of generalized anxiety disorders. Two studies $(22,23)$ that investigated the effect of buspirone on anxiety, dyspnea and exercise tolerance in patients with COPD were identified. Both studies were short term (a few weeks), randomized, placebo-controlled, crossover trials in a small number of subjects $(n=11$ and $n=16)$ with stable COPD. There were conflicting results for the relief of dyspnea during exercise, improvement in exercise tolerance and anxiety between these two studies. Buspirone was generally well tolerated, with three subjects in one study (23) withdrawing due to dizziness and fatigue.
Three randomized placebo-controlled trials (RCTs) investigating the role of different tricyclic antidepressant medications in COPD were identified (24-26). Two studies that included patients with a history of depression $(24,25)$ demonstrated no improvement in exercise tolerance as assessed by $12 \mathrm{MWT}$. HRQoL improved in one (25) of two studies $(25,26)$ as assessed by the sickness impact profile. In one small study of 12 subjects (24), improvement in 12MWT distance correlated with improvement in anxiety and depression scores. Antidepressant medication did not significantly improve dyspnea scores during daily activities $(25,26)$ or a 12MWT $(25)$. Anticholinergic side effects were common, occasionally leading to discontinuation of medication.

Another class of antidepressant medications with possible anxiolytic properties - the selective serotonin-reuptake inhibitors (SSRIs) - have also been used to treat patients with COPD and depressive symptoms. Four small studies were identified - two case series (27 [n=7], 28 [n=14]) and two RCTs (29 [n=23], 30 [n=28]). In one of the case series (27), all seven subjects reported a subjective improvement in dyspnea, whereas there was no difference in dyspnea domain score of the chronic respiratory questionnaire between SSRIs and placebo in an RCT (29). There was no significant change in 6 min walk test distance $(30)$ or HRQoL $(29,30)$. In general, there was low acceptance of treatment with SSRIs by the study subjects, primarily due to side effects.

\footnotetext{
Question \#1

Do anxiolytic and antidepressant medications reduce dyspnea and improve QoL in stable patients with advanced COPD compared with usual care (control population)?

The following recommendation is based on evidence from 13 studies and expert consensus of the CTS COPD expert panel.

\section{Recommendation \#1}

We recommend that anxiolytic and antidepressant medications not be routinely used for the management of dyspnea in patients with advanced COPD. (Grade of recommendation 2B)
}

\section{Conclusions}

The results of these studies demonstrate little or conflicting evidence supporting the use of benzodiazepines, buspirone, tricyclic antidepressants or SSRIs to relieve dyspnea in patients with advanced COPD. The impact of these medications on HRQoL was infrequently reported. The burden to patients related to side effects was significant, particularly for tricyclic and SSRI antidepressant medications. Larger RCTs assessing the effectiveness of anxiolytic medications using validated measurement tools for dyspnea and HRQoL in patients with COPD are required. 


\section{SECTION II}

\section{Question}

Do opioids reduce dyspnea and improve QoL in stable patients with advanced COPD when used as an adjunct to optimal conventional treatment?

\section{Introduction}

Dyspnea is refractory to conventional treatment for up to $50 \%$ of patients with advanced COPD (31). Opioids have been advocated as a potential treatment for refractory dyspnea in this population (32-34). It has been postulated that opioids modulate dyspnea via the following mechanisms: reducing minute ventilation, increasing ventilatory efficiency during exercise, reducing ventilatory responses to hypoxemia and hypercapnia, and effecting bronchoconstriction (1). Therefore, the Committee sought to explore the evidence regarding the use of opioids to treat dyspnea in patients with advanced COPD.

\section{Key evidence}

The literature search identified 165 citations, of which 156 were excluded after review. Of the nine citations meeting the inclusion criteria, one was a systematic review (34), which included four of the remaining citations and referred to 14 additional studies not identified in the search. Of the remaining four citations, one study was a four-day crossover RCT (35), one was a meta-analysis of the effects of nebulized opioids (36), one concerned epidural use of methadone (37) and one was an abstract of a substudy that focused on opioid responsiveness, which was subsequently published as a full-length article (38). The systematic review published in 2002 by Jennings et al (34) concluded that oral opioids (in 116 subjects) were effective in the treatment of dyspnea ( $16 \%$ improvement in dyspnea intensity; $\mathrm{P}<0.001$ ), while nebulized opioids were not; the latter was confirmed in a metaanalysis published later (36). All studies included in the two reviews were small. Jennings et al (34) reviewed 18 RCTs, the largest of which included 19 patients; there were nine single-dose studies of a nebulized opioid, and of nine studies involving either oral $(n=8)$ or subcutaneous opioids $(n=1)$, five were single- and four were multidose studies, one of diamorphine (39) (not available in Canada), two of dihydrocodeine $(40,41)$ and one of morphine $(42)$. Primary outcome measures have focused on dyspnea scores, and only one study reported an HRQoL assessment (chronic respiratory questionnaire) with an overall neutral effect (42).

The Committee formally extended the search of the Cochrane, EMBASE and Medline databases to February 5, 2010, revealing a 2010 update of the Jennings et al systematic review that included only one new RCT (35) involving 48 patients in a four-day crossover trial of sustained-release morphine $(20 \mathrm{mg})$ versus placebo. In this, the only adequately powered multidose RCT published to date, morphine conferred beneficial effects on both morning $(\mathrm{P}=0.01)$ and evening $(\mathrm{P}<0.05)$ visual analogue scores of dyspnea, and beneficial effects on sleep $(\mathrm{P}=0.04)$.

Given the dearth of adequately powered, clinically relevant RCTs, we have included mention of a significant body of work published to date in abstract form only (43). This concerns an open-label dosefinding study of 48 patients with COPD taking $10 \mathrm{mg}, 20 \mathrm{mg}$ or $30 \mathrm{mg}$ of sustained-release morphine daily. Follow-up was for a minimum of three months, and using an assessment of 'overall clinical benefit', $51 \%$ of patients experienced sufficient benefit from fixed-dose opioids that they desired to continue therapy.

\section{Conclusions}

The evidence suggests that opioids reduce dyspnea in stable patients with advanced COPD when used as an adjunct to optimal conventional treatment. The American College of Chest Physicians recently released a consensus statement regarding the management of dyspnea in patients with advanced lung and heart disease (11), and also concluded that opioids should be considered and titrated for relief of dyspnea in the individual patient.

\section{Question \#2}

Do opioids reduce dyspnea and improve QoL in stable patients with advanced COPD when used as an adjunct to optimal conventional treatment?

The following recommendation is based on evidence from 10 studies and expert consensus of the CTS COPD expert panel.

\section{Recommendation \#2}

We recommend that oral (but not nebulized) opioids be used for the treatment of refractory dyspnea in the individual patient with advanced COPD. (Grade of recommendation 2C)

\section{SECTION III}

\section{Question}

Do nonpharmacological interventions (use of a fan, chest vibration techniques, pursed-lip breathing, meditation, relaxation therapy or behavioural techniques) reduce dyspnea and improve QoL in stable patients with advanced COPD compared with usual care (control population)?

\section{Introduction}

Pharmacological interventions alone do not typically provide adequate relief of dyspnea for some individuals (44). Nonpharmacological therapies that modify the emotional and/or cognitive experience of dyspnea may be helpful in reducing breathlessness in the clinical setting. The Comittee reviewed the evidence regarding the efficacy of nonpharmacological interventions to reduce dyspnea.

\section{Key evidence}

The literature search identified 310 citations, of which 294 were excluded after review. A total of 14 studies with 1070 participants satisfied the inclusion criteria, while the remaining two articles were systematic reviews. Two studies $(45,46)$ examined the effects of chest wall vibration, while four studies investigated the effects of pursed-lip breathing on dyspnea (47-50). Three studies addressed aspects of self-efficacy: dyspnea self-management to improve self-efficacy for dyspnea and walking (51); cognitive behavioral therapy and COPD education (52); and a self-management program (53). One systematic review (54) noted that all chronic disease management projects involving primary care for individuals with COPD showed improved QoL; however, the quality of the RCTs was not optimal and more research is needed in this area, including in populations that are clinically meaningful. Two methods of relaxation were examined by Louie (55). Single studies investigating the following interventions were identified: singing (56); heart rate variability biofeedback (57); and specialized respiratory home nursing care (58).

The 2008 Cochrane systematic review on nonpharmacological interventions for breathlessness in advanced stages of malignant and nonmalignant disease (44) yielded evidence on nonpharmacological strategies specific to patients with COPD that had not been identified in the initial literature search. These included RCTs (1996 to 2008) of acupuncture/acupressure (59-61), distractive auditory stimuli (music) (62-66), walking aids (67-72), chest wall vibration (73), neuromuscular stimulation (74-76), use of a handheld fan (77), counselling and support (78), breathing retraining (79), case management $(80,81)$ and psychotherapy (82). In total, they constituted 24 additional articles that met the criteria for the present review, with the extracted data used to inform the recommendations.

\section{Conclusions}

Much of the evaluation of nonpharmacological interventions for the relief of dyspnea has involved subjects with COPD, although not necessarily in persons with advanced disease.

In accordance with the conclusions of Bausewein et al (44), we agree that the evidence supporting neuromuscular electrical muscle stimulation (NMES) is quite strong. NMES over four to six weeks 
helps to relieve breathlessness in patients with COPD, which may be especially helpful for persons who are not capable of exercise. All studies showed that NMES improved dyspnea, muscle strength and performance in daily tasks.

Chest wall vibration is another nonpharmacological therapy that has strong supportive evidence for relief of breathlessness, although the chest wall vibration studies have only been tested in a laboratory setting. Although the exact process remains to be determined, the underlying mechanism of chest wall vibration is possibly related to the activation of muscle spindles in the intercostal muscles, with consequent modification of respiratory sensations.

Moderate evidence supports the use of walking aids, such as rollators, and breathing training. The positive effect of a walking aid on dyspnea is likely the result of the decreased work of breathing by bracing the $\operatorname{arm}(\mathrm{s})$ on the aid and assuming a forward-leaning posture. In addition, stabilization of the ribcage may improve accessory muscle function, thereby allowing these muscles to be engaged in respiratory efforts. Breathing training may take the form of pursed-lip or diaphragmatic breathing. Pursed-lip breathing may decrease respiratory rate and increase vital capacity, thereby improving gas exchange.

There is insufficient evidence and a lack of consensus to make an overall recommendation on the effectiveness of other general nonpharmacological interventions for reducing dyspnea and improving QoL in stable patients with COPD. At this time, there is insufficient evidence to recommend the routine use of acupuncture, acupressure, distractive auditory stimuli (music), relaxation, handheld fans, counselling and support programs, or psychotherapy.

\section{Question \#3}

Do nonpharmacological interventions (use of a fan, chest vibration techniques, pursed-lip breathing, meditation, relaxation therapy or behavioural techniques) reduce dyspnea and improve QoL in stable patients with advanced COPD compared with usual care (control population)?

The following recommendations are based on evidence from 38 studies and expert consensus of the CTS COPD expert panel.

\section{Recommendation \#3a}

NMES and chest wall vibration are helpful in reducing dyspnea in patients with COPD. We recommend that NMES and chest wall vibration, undertaken by knowledgeable providers, be used in the management of dyspnea in patients with advanced COPD. (Grade of recommendation $2 \mathrm{~B}$ )

\section{Recommendation \#3b}

COPD patients with dyspnea benefit from the use of walking aids. It is recommended that patients with advanced COPD be informed of the potential benefits of walking aids and undergo professional assessment for choosing a suitable device. (Grade of recommendation 2B)

\section{Recommendation \#3c}

Pursed-lip breathing can be an effective strategy for relief of dyspnea. It is recommended that patients with advanced COPD be informed of the potential benefits of pursed-lip breathing and be instructed in its use. (Grade of recommendation 2B)

There is insufficient evidence to recommend the routine use of acupuncture, acupressure, distractive auditory stimuli (music), relaxation, handheld fans, counselling and support programs, or psychotherapy.

\section{SECTION IV}

\section{Question}

Does supplemental oxygen reduce dyspnea and improve QoL in stable patients with advanced COPD compared with usual care (control population) in patients with hypoxemia, and in patients without hypoxemia?

\section{Introduction}

Long-term oxygen therapy (LTOT) is regularly used in the management of patients with COPD complicated by severe hypoxemia. Two RCTs, published almost 30 years previously $(83,84)$, established the significant survival benefit of LTOT when used for at least $15 \mathrm{~h}$ /day in hypoxemic COPD patients. On the other hand, a more recent study in COPD patients with moderate hypoxemia $\left(\mathrm{PaO}_{2}\right.$ of $56 \mathrm{mmHg}$ to $65 \mathrm{mmHg}$ ) (85) did not demonstrate a survival benefit from oxygen therapy, although many subjects used oxygen for less than $15 \mathrm{~h}$ /day.

Many studies have also demonstrated improvement in exercise capacity and dyspnea from the use of intermittent, short-term ambulatory oxygen in patients with COPD. These studies have been systematically reviewed elsewhere $(86,87)$. Multifactorial mechanisms have been proposed to explain the improvements in exercise performance with hyperoxia, including reduced respiratory frequency and minute ventilation, reduced dynamic hyperinflation and decreased dyspnea $(88,89)$. The short-term use of supplemental oxygen in patients with advanced COPD has also been examined. Some studies reported a reduction in dyspnea with supplemental oxygen administration $(90,91)$, while others did not $(87,88,92)$.

It is unclear whether improvements in survival using LTOT or in exercise performance during short-burst oxygen use during laboratory or field exercise tests also translate into improvements in dyspnea experienced by patients with advanced COPD. Therefore, the committee examined whether the use of supplemental oxygen reduced dyspnea in patients with advanced COPD with or without hypoxemia.

\section{Key evidence}

Sixty-nine abstracts were initially identified in the search process, of which 28 were selected for complete review. Twelve studies fully met the inclusion criteria and were selected for data extraction.

Six studies examined the role of LTOT in COPD patients with severe resting hypoxemia. The earliest published study reviewed was a randomized, double-blind, placebo-controlled crossover trial (93) (five weeks in each arm with a two-week washout) of oxygen versus air in nine subjects with COPD. There was no significant difference in activity levels with oxygen versus air. Three studies compared COPD subjects on oxygen therapy $(n=23$ to $n=55)$ with COPD case controls $(\mathrm{n}=18$ to $\mathrm{n}=53)$ for six months (94-96). A low baseline HRQoL in COPD subjects requiring LTOT compared with COPD control subjects matched for age, sex and degree of airflow obstruction was noted in two studies $(95,96)$. One study (94) documented slight improvement in neuropsychiatric functioning, but not in HRQoL with LTOT, while another reported no improvement in HRQOL with LTOT. In contrast, a significant improvement in HRQoL, but not in exercise capacity, anxiety or depression scores, was recently found (96). Finally, two prospective studies followed 26 and 114 COPD patients on LTOT for six months (97) and 12 months (98), respectively. Both studies reported limited effects of LTOT on HRQoL, depression or other psychological measures.

Six studies examined the role of ambulatory oxygen in COPD: four studies in subjects not on LTOT (ie, without severe resting hypoxemia) (99-102), one study in subjects on continuous LTOT for severe resting hypoxemia (103) and one study that included both groups of COPD subjects (104). All studies were randomized and double-blinded (oxygen versus air cylinders), and ranged from eight to 36 weeks in duration using different study designs. In COPD subjects without severe resting hypoxemia, ambulatory oxygen was reported to have no benefit compared with air in terms of changes in HRQoL or dyspnea in three of the four studies. In addition, acute effects of oxygen administered during a field or laboratory exercise test could not predict who would respond to ambulatory oxygen at home. The addition of ambulatory oxygen to COPD subjects already on continuous LTOT for severe resting hypoxemia resulted in no improvement in dyspnea, HRQoL or exercise capacity (103). Similarly, Sandland et al (104) reported no significant improvements in dyspnea, HRQoL or activity level. Most recently, a double-blinded RCT of air versus oxygen (105) 


\section{TABLE 3}

\section{Summary of evidence-based recommendations and grading}

\begin{tabular}{|c|c|c|}
\hline Recommendation & Description & Grade \\
\hline 1 & $\begin{array}{l}\text { We recommend that anxiolytic and antidepressant medications not be routinely used for the management of dyspnea in patients } \\
\text { with advanced COPD }\end{array}$ & $2 \mathrm{~B}$ \\
\hline 2 & $\begin{array}{l}\text { We recommend that oral (but not nebulized) opioids be used for the treatment of dyspnea in the individual patient with advanced } \\
\text { COPD }\end{array}$ & $2 \mathrm{C}$ \\
\hline $3 a$ & $\begin{array}{l}\text { Neuromuscular electrical stimulation and chest wall vibration are helpful in reducing dyspnea in COPD. We recommend that } \\
\text { neuromuscular electrical stimulation and chest wall vibration, undertaken by knowledgeable providers, be utilized in the man- } \\
\text { agement of dyspnea in advanced COPD patients }\end{array}$ & $2 \mathrm{~B}$ \\
\hline $3 b$ & $\begin{array}{l}\text { COPD patients with dyspnea benefit from the use of walking aids. It is recommended that patients with advanced COPD be } \\
\text { informed of the potential benefits of walking aids, and undergo professional assessment for a suitable walking aid }\end{array}$ & $2 \mathrm{~B}$ \\
\hline $3 c$ & $\begin{array}{l}\text { Pursed-lip breathing can be an effective strategy for relief of dyspnea. It is recommended that patients with advanced COPD be } \\
\text { informed of the potential benefits of pursed-lip breathing and be instructed in its use }\end{array}$ & $2 \mathrm{~B}$ \\
\hline 4 & $\begin{array}{l}\text { Continuous oxygen therapy for hypoxemic COPD patients reduces mortality, and may reduce dyspnea in some patients. The } \\
\text { CTS has previously recommended that patients with advanced COPD who are hypoxemic at rest receive long-term continuous } \\
\text { oxygen therapy because of a mortality benefit. Oxygen therapy may also provide symptomatic benefit by reducing dyspnea } \\
\text { when administered at rest to hypoxemic patients with advanced COPD }\end{array}$ & $2 \mathrm{~B}$ \\
\hline
\end{tabular}

COPD Chronic obstructive pulmonary disease; CTS Canadian Thoracic Society

demonstrated similar reductions in dyspnea in stable nonhypoxemic patients with refractory dyspnea (64\% of the study population had COPD).

\section{Conclusions}

While oxygen therapy is the standard of care for the treatment of hypoxemic patients with advanced COPD, only a few studies have objectively assessed the short-term effects of supplemental oxygen therapy on dyspnea at rest in patients with advanced COPD, and the results were mixed. Short-term supplemental oxygen with activity may improve exercise performance, enhance exercise training and reduce dyspnea in patients with COPD.

There is no evidence to support or not support the use of supplemental oxygen at rest or with activity in nonhypoxemic patients with advanced COPD.

\section{Question \#4}

Does supplemental oxygen reduce dyspnea and improve QoL in stable patients with advanced COPD compared with usual care in patients with hypoxemia, and in patients without hypoxemia?

The following recommendation is based on evidence from 10 studies and expert consensus of the CTS COPD expert panel.

\section{Recommendation \#4}

Continuous oxygen therapy for hypoxemic COPD patients reduces mortality, and may reduce dyspnea in some patients. The CTS has previously recommended that patients with advanced COPD who are hypoxemic at rest receive long-term continuous oxygen therapy because of a mortality benefit. Oxygen therapy may also provide symptomatic benefit by reducing dyspnea when administered at rest to hypoxemic patients with advanced COPD. (Grade of recommendation 2B)

There is no evidence to support the routine use of supplemental oxygen to reduce dyspnea in nonhypoxemic patients with advanced COPD. There appears to be little benefit from supplemental oxygen on QoL in patients with advanced COPD.

\section{DISCUSSION}

The present guidelines process was initiated with the belief, shared by others (11), that many patients with advanced COPD are not currently being treated consistently and effectively for relief of dyspnea. The purpose was to provide guidance to improve the treatment of dyspnea in this patient population. The present clinical practice guideline has addressed several clinically meaningful questions regarding the management of dyspnea in patients with advanced COPD, using an evidencebased, systematic review process led by a representative interprofessional panel of experts in the field. The evidence from the literature reviews, and the experience and guidance afforded by the expert working group members enabled the formulation of relevant recommendations, fully recognizing that there are significant and large gaps in the scientific literature in this area (Table 3).

The evidence supports the benefits of oral (but not nebulized) opioids, NMES, chest wall vibration, walking aids and pursed-lip breathing in the management of dyspnea in the individual patient with advanced COPD. Supplemental oxygen is recommended for COPD patients with significant resting hypoxemia, but its use for the targeted management of dyspnea in this setting should be reserved only for patients who receive symptomatic benefit.

There is insufficient evidence in the literature to support the routine use of anxiolytic medications, nebulized opioids, acupuncture, acupressure, distractive auditory stimuli (music), relaxation, handheld fans, counselling and support programs, or psychotherapy. There is also no evidence to support the routine use of supplemental oxygen to reduce dyspnea in nonhypoxemic patients with advanced COPD.

To better manage dyspnea in this setting, it is vital to appreciate and understand its presence and severity.

Furthermore, for these recommendations to be applied in the management of dyspnea in patients with COPD, clinicians and clinical documentation must regularly and serially assess the patient experience of dyspnea. Multiple tools exist for assessing dyspnea and, although no consensus exists for the correct clinical assessment strategy, other bodies have suggested that, at a minimum, some measure of the symptom intensity and some inquiry into the distress to the patient associated with the dyspnea be used to guide management (11,106-108). Patients with advanced COPD should be routinely asked to rate the intensity of their shortness of breath as a fundamental aspect of their care (11). In addition, appropriate pharmacological therapies - including short- and long-acting bronchodilator therapies, inhaled corticosteroids in combination with long-acting beta-2 agonists and theophylline preparations as well as nonpharmacological therapies including pulmonary rehabilitation should be appropriately used in the management of dyspnea for patients with advanced COPD $(109,110)$.

Opioids are infrequently prescribed in this setting, despite the evidence supporting their benefit. Several issues contribute to this reality including unfamiliarity with dosing, concerns regarding respiratory depression and/or addiction, the fear of other significant side effects, as well as concerns and attitudes about addiction and dependence. An additional obstacle to the optimal management of dyspnea in advanced COPD has been a lack of attention in some clinical guideline statements. Standards from the European Respiratory Society and the American Thoracic Society make no recommendation (111) regarding opioid use. An earlier consensus document from the American 


\section{TABLE 4}

\section{Suggested protocol for managing dyspnea with opioid therapy in advanced chronic obstructive pulmonary disease patients}

- Initiate opioid therapy with oral immediate-release morphine syrup titrate slowly at weekly intervals over a 4- to 6-week period

- Start therapy with morphine $0.5 \mathrm{mg}$ orally twice daily for 2 days, and then increase to $0.5 \mathrm{mg}$ orally every $4 \mathrm{~h}$ while awake for remainder of week 1

- If tolerated and indicated, increase to morphine $1.0 \mathrm{mg}$ orally every $4 \mathrm{~h}$ while awake in week 2 , increasing by $1.0 \mathrm{mg} /$ week or $25 \%$ dosage increments/week until the lowest effective dose that appropriately manages the dyspnea is achieved

- Once a stable dosage is achieved (ie, no significant dose change for 2 weeks and dyspnea managed), a sustained-release preparation at a comparable daily dose could be considered for substitution

- If patients experience significant opioid-related side effects such as nausea or confusion, substitution of an equipotent dose of oral hydromorphine could be considered ( $1 \mathrm{mg}$ hydromorphine $=5 \mathrm{mg}$ morphine)

- Stool softeners and laxatives should be routinely offered to prevent opioid-associated constipation

Adapted from references 1, 109 and 115

Thoracic Society (112) specifically recommended against the use of opioids in patients with COPD except in the terminal stages. The Global Initiative for Chronic Obstructive Lung Disease stated that “... some clinical studies suggest morphine used to control dyspnea may have serious adverse effects and its benefits may be limited to a few sensitive individuals" (113), although that concern has recently been challenged (1). Conversely, the Canadian (109) and Australian (114) COPD guidelines included recommendations for considering opioids in the management of severe dyspnea. The Canadian COPD guidelines published in 2007 (109) specifically stated that "opioids remain the most effective dyspnea-relieving medication in end-of-life care", and included a table listing various opioid medications, mode of administration and commonly used dosages. The recent policy statement from the American College of Chest Physicians (6) and the American Thoracic Society statement (5) on palliative and end-of-life care also appropriately addressed the use of opioids in this setting.

Although providing a pathway for prescribing opioid therapy in patients with advanced COPD was not an intended goal, the Committee did recognize and appreciate the current unfamiliarity with prescribing and dosing. A potential approach to the initiation and continuation of opioid therapy targeted to managing dyspnea in patients with advanced COPD is provided in Table 4 (1), and has been discussed elsewhere $(109,115)$. The role of opioid therapy and other therapies in the comprehensive management of refractory dyspnea in patients with advanced COPD is outlined in Figure 1.

\section{FUTURE RESEARCH NEEDS}

It has become apparent from this process that there is a paucity of highquality evidence, scientific literature and information regarding this topic. Further study is required to address many important clinical questions, and to provide further understanding of dyspnea in this setting. Larger RCTs assessing the effectiveness of anxiolytic medications using validated measurement tools for dyspnea and HRQOL in COPD are required. The contributions and effects of managing depression and anxiety on dyspnea also require further study. Research of the use of supplemental oxygen in this setting is necessary. Regarding opioids, several important clinical questions remain unanswered (1). Although opioids have proven to be beneficial, the optimal initiation dose, dosing interval, titration schedule and delivery route are not well understood. To what degree are beneficial effects or adverse effects of opioids sustained over time? Can the available data supporting oral opioids for dyspnea translate to intravenous therapy as it does in general palliative care management for those patients unable to use the oral route? Does adherence to opioid therapy change over time, and what are the

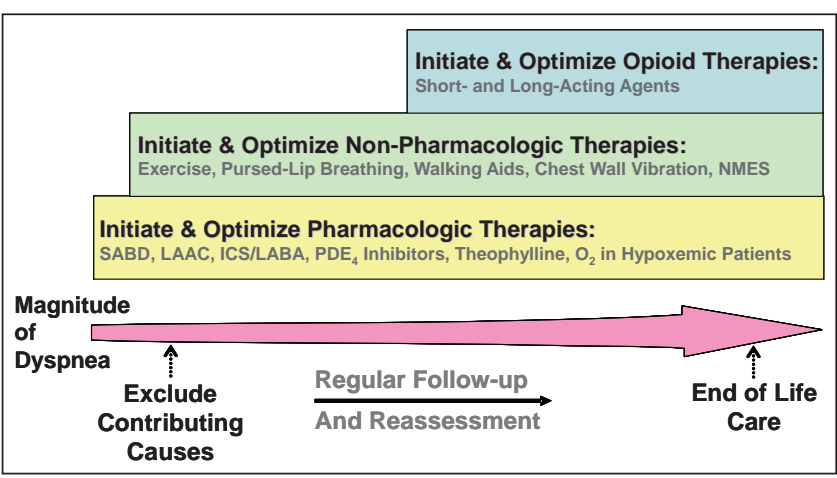

Figure 1) Comprehensive approach to management of dyspnea in patients with advanced chronic obstructive pulmonary disease (COPD). ICS Inhaled corticosteroids; LAAC Long-acting anticholinergics; LABA Long-acting beta-2 agonists; NMES Neuromuscular electrical stimulation; $\mathrm{O}_{2}$ Oxygen; $\mathrm{PDE}_{4}$ Phosphodiesterase 4; SABD Short-acting bronchodilators. Adapted from references 109,110 and 115

factors (ie, side effects, patient/caregiver fears or misconceptions about addiction and dependence, or fears about opioids hastening death) that influence adherence? Are some opioids more efficacious or tolerated better than others? Are patients with advanced COPD at a higher risk of opioid-induced complications than other patients with severe dyspnea, and are conventional concerns with appropriately dosed and monitored opioids in patients with hypercapnia justified? Other important areas also require further study including whether the benefits from NMES realized in the research laboratory are fully transferable to the clinical setting. These important research questions require attention to advance our understanding in this area.

\section{KNOWLEDGE TRANSFER AND TOOLS FOR PRACTICE}

In addition to publication, the present document will be posted at www.respiratoryguidelines.ca and www.pulsus.com for viewing and download. A teaching and dissemination slide kit, complementing existing CTS teaching aids for the diagnosis and management of COPD, is being developed and will be similarly posted for viewing and download. Patient/family/caregiver and health care professional information sheets (two in total) will be posted for viewing and download, and also further disseminated by the Canadian and provincial lung associations. Finally, a trifold pocket 'Slim Jim' summarizing key recommendations and information from this clinical practice guideline will be forwarded to all family physicians in Canada, provincial Ministries of Health, and selected provincial and regional health authorities.

The Working Group recognized and acknowledged potential barriers to the more widespread use of opioids in this setting, the lack of specific protocols and familiarity with the use of NMES, and the potential limitation of sufficiently trained individuals to deliver these effective techniques. The Committee is hopeful that the present document and the above tools and strategies will assist in the meaningful dissemination and implementation of the recommendations from the present guideline statement into clinical practice.

It is also recommended that the development of reliable and responsive quality measures in dyspnea management - grounded in the recommendations presented in the current document - will facilitate the evaluation, implementation and health care delivery improvement in this setting (106).

EDITORIAL INDEPENDENCE: The COPD Committee Dyspnea Expert Working Group is functionally and editorially independent from any funding sources of the CTS. The Dyspnea Expert Working Group and the COPD Committee do not receive any funding from external sources. The Expert Working Group was formed by the CTS COPD Committee, which is accountable to the CTS Respiratory Guidelines Committee and the CTS Board of Directors. 
CONFLICTS OF INTEREST: Members of the COPD Committee Dyspnea Expert Working Group declared potential conflicts of interest at the time of appointment, and these were updated throughout the development process. Individual member conflict of interest statements are posted at http://www.respiratoryguidelines.ca/guideline/ chronic-obstructive-pulmonary-disease.

ACKNOWLEDGEMENTS: Members of the COPD Committee Dyspnea Expert Working Group thank the CTS Respiratory Guidelines Committee for their expert guidance and support.

\section{REFERENCES}

1. Rocker G, Horton R, Currow D, Goodridge D, Young J, Booth S. Palliation of dyspnoea in advanced COPD: Revisiting a role for opioids. Thorax 2009;64:910-5.

2. Edmonds P, Karlsen S, Khan S, Addington-Hall J. A comparison of the palliative care needs of patients dying from chronic respiratory diseases and lung cancer. Pall Med 2001;15:287-95.

3. Goodridge D Lawson J, Rocker G, Marciniuk D, Rennie D. Factors associated with opioid dispensation for patients with COPD and lung cancer in the last year of life: A retrospective analysis. Int J Chron Obstruct Pulmon Dis 2010;6:99-105.

4. Goodridge D, Lawson J, Duggleby W, Marciniuk D, Rennie D, Stang M. Health care utilization of patients with chronic obstructive pulmonary disease and lung cancer in the last 12 months of life. Resp Med 2008;102:885-91.

5. Lanken PN, Terry PB, Delisser HM, et al; ATS End-of-Life Care Task Force. An official American Thoracic Society clinical policy statement: Palliative care for patients with respiratory diseases and critical illnesses. Am J Respir Crit Care Med 2008;177:912-27.

6. Selecky PA, Eliasson CA, Hall RI, Schneider RF, Varkey B, McCaffree DR; American College of Chest Physicians. Palliative and end-of-life care for patients with cardiopulmonary diseases: American College of Chest Physicians position statement. Chest 2005;128:3599-610.

7. Rocker GM, Dodek PM, Heyland DK. Toward optimal end-of-life care for patients with advanced chronic obstructive pulmonary disease: Insights from a multicentre study. Can Respir J 2008;15:249-54.

8. O'Donnell DE, Banzett RB, Carrieri-Kohlman V, et al. Pathophysiology of dyspnea in chronic obstructive pulmonary disease: A roundtable. Proc Am Thorac Soc 2007;4:145-68.

9. Burki N, Lee L-Y. Mechanisms of dyspnea. Chest 2010;138:1196-201.

10. Manning HL, Schwartzstein RM. Pathophysiology of dyspnea. N Engl J Med 1995;333:1547-53.

11. Mahler DA, Selecky P, Harrod CG, et al. American College of Chest Physician's consensus statement on the management of dyspnea in patients with advanced lung or heart disease. Chest 2010;137:674-91.

12. Brouwers M, Kho KE, Browman GP, et al; AGREE Next Step Consortium. AGREE II: Advancing guideline development, reporting, and evaluation in healthcare. CMAJ 2010;182:E839-42.

13. Guyatt G, Gutterman D, Baumann M, et al. Grading strength of recommendations and quality of evidence in clinical guidelines: Report from an American College of Chest Physicians Task Force. Chest 2006;129:178-81.

14. Harbour R, Miller J. A new system for grading recommendations in evidence based guidelines. BMJ 2001;323:334-6.

15. Ries AL, Bauldoff GS, Carlin BW, et al. Pulmonary Rehabilitation. Joint ACCP/AACVPR evidence-based clinical practice guidelines. Chest 2007;131:4S-42S.

16. Hill K, Geist R, Goldstein RS, Lacasse Y. Anxiety and depression in end-stage COPD. Eur Respir J 2008;31:667-77.

17. Maurer J, Rebbapragada V, Borson S, et al. Anxiety and depression in COPD: Current understanding, unanswered questions and research needs. Chest 2008;134:43S-56S.

18. Mitchell-Heggs P, Murphy K, Minty K, et al. Diazepam in the treatment of dyspnea in the pink puffer syndrome. Q J Med 1980;193:9-20.

19. Woodcock AA, Gross E, Geddes DM. Drug treatment of breathlessness: Contrasting effects of diazepam and promethazine in pink puffers. BMJ 1981;283:343-6.
20. Man GCW, Hsu K, Sproule BJ. Effect of alprazolam in patients with chronic obstructive pulmonary disease. COPD 1986;90:832-6.

21. Greene JG, Pucino F, Carlson JD, Storsved M, Strommen GL. Effects of alprazolam on respiratory drive, anxiety, and dyspnea in chronic airflow obstruction: A case study. Pharmacotherapy 1989;9:34-8.

22. Argyropoulou P, Patakas D, Koukou A, Vasiliadis P, Georgopoulos D. Buspirone effect on breathlessness and exercise performance in patients with chronic obstructive pulmonary disease. Respiration 1993;60:216-20.

23. Singh NO, Despars JA, Stansbury DW, Avalos K, Light RW. Effects of buspirone on anxiety levels and exercise tolerance in patients with chronic airflow obstruction and mild anxiety. Chest 1993;103:800-4.

24. Light RW, Merrill EJ, Despars J, Gordon GH, Mutalipassi LR. Doxepin treatment of depressed patients with chronic obstructive pulmonary disease. Arch Intern Med 1986;146:1377-80.

25. Borson S, McDonald GJ, Gayle T, Deffebach M, Lakshminarayan S, VanTuinen C. Improvement in mood, physical symptoms, and function with nortriptyline for depression in patients with chronic obstructive pulmonary disease. Psychosomatics 1992;33:190-201.

26. Strom K, Boman G, Pehrsson K, et al. Effect of protriptyline, $10 \mathrm{mg}$ daily, on chronic hypoxaemia in chronic obstructive pulmonary disease. Eur Respir J 1995;8:425-9.

27. Smoller JW, Pollack MH, Systrom D, Kradin RL. Sertraline effects on dyspnea in patients with obstructive airways disease. Psychosomatics 1998;39:24-9.

28. Yohannes AM, Connolly MJ, Baldwin RC. A feasibility study of antidepressant drug therapy in depressed elderly patients with chronic obstructive pulmonary disease. Inter J of Geriatr Psychiatry 2001;16:451-4.

29. Lacasse Y, Beaudoin L, Rousseau L, Maltais F. Randomized trial of paroxetine in end-stage COPD. Monaldi Arch Chest Dis 2004;61:140-7.

30. Eiser N, Harte R, Karvounis S, Phillips C, Isaac MT. Effect of treating depression on quality of life and exercise tolerance in severe COPD. COPD 2005;2:33-41.

31. lkington $\mathrm{H}$, White P, Addington-Hall J, Higgs R, Pettinari C. The last year of life of COPD: A qualitative study of symptoms and services. Respir Med 2004;98:439-45.

32. Dean MM. End-of-life care for COPD patients. Prim Care Respir J 2008;17:46-50.

33. Spathis A, Booth S. End of life care in chronic obstructive pulmonary disease: In search of a good death. Int J Chron Obstruct Pulmon Dis 2008;3:11-29.

34. Jennings AL, Davies AN, Higgins JP, Gibbs JS, Broadley KE. A systematic review of the use of opioids in the management of dyspnoea. Thorax 2002;57:939-44.

35. Abernethy AP, Currow DC, Frith P, Fazekas BS, McHugh A, Bui C. Randomised, double blind, placebo controlled crossover trial of sustained release morphine for the management of refractory dyspnoea. BMJ 2003;327:523-8.

36. Brown SJ, Eichner SF, Jones JR. Nebulized morphine for relief of dyspnea due to chronic lung disease. Ann Pharmacother 2005;39:1088-92.

37. Juan G, Ramon M, Valia JC, et al. Palliative treatment of dyspnea with epidural methadone in advanced emphysema. Chest 2005;128:3322-8.

38. Currow DC, Plummer J, Frith P, Abernethy AP. Can we predict which patients with refractory dyspnea will respond to opioids? J Palliat Med 2007;10:1031-6.

39. Eiser N, Denman WT, West C, Luce P. Oral diamorphine: Lack of effect on dyspnoea and exercise tolerance in the "pink puffer" syndrome. Eur Respir J 1991;4:926-31.

40. Woodcock AA, Gross ER, Gellert A, Shah S, Johnson M, Geddes DM. Effects of dihydrocodeine, alcohol, and caffeine on breathlessness and exercise tolerance in patients with chronic obstructive lung disease and normal blood gases. N Engl J Med 1981;305:1611-6.

41. Johnson MA, Woodcock AA, Geddes DM. Dihydrocodeine for breathlessness in "pink puffers". Br Med J (Clin Res Ed) 1983;286:675-7.

42. Poole PJ, Veale AG, Black PN. The effect of sustained-release morphine on breathlessness and quality of life in severe chronic obstructive pulmonary disease. Am J Respir Crit Care Med $1998 ; 157: 1877-80$ 
43. Currow DC, McDonald C, Oaten S, et al. Once daily opioids for chronic dyspnoea: A dose increment and pharmacovigilance study. J Palliat Med 2010 (In Press).

44. Bausewein C, Booth S, Gysels M, Higginson IJ. Non-pharmacological interventions for breathlessness in advanced stages of malignant and non-malignant disease. Cochrane Database Syst Rev 2008;2:CD005623.

45. Cristiano LM, Schwartzstein R. The effect of chest wall vibration on dyspnea during hypercapnia and exercise in chronic obstructive pulmonary disease. Am J Resp Crit Care Med 1997;155:1552-9.

46. Fujie T, Tojo N, Inase N, Nara N, Homma I, Yoshizawa Y. Effect of chest wall vibration on dyspnea during exercise in chronic obstructive pulmonary disease. Resp Phys Neurobiol 2002;130:305-16.

47. Faager $G$, Stahle A, Larsen FF. Influence of spontaneous pursed lip breathing on walking endurance and oxygen saturation in patients with moderate to severe chronic obstructive pulmonary disease. Clin Rehab 2008;22:675-83.

48. Garrod R, Dallimore K, Cook J, Davies V, Quade K. An evaluation of the acute impact of pursed lips breathing on walking distance in non spontaneous pursed lips breathing chronic obstructive pulmonary disease patients. Chron Respir Dis 2005;2:67-72.

49. Nield MA, Soo HGW, Roper JM, Santiago S. Efficacy of pursed lip breathing: A breathing pattern retraining strategy for dyspnea reduction. J Cardiopulm Rehab Prev 2007;27:237-44.

50. Spahija J, De Marchie M, Grassino A. Effects of imposed pursed lips breathing on respiratory mechanics and dyspnea at rest and during exercise in COPD. Chest 2005;128:640-50.

51. Davis AHT, Carrieri-Kohlman V, Janson SL, Gold WM, Stulbarg MS. Effects of treatment on two types of self-efficacy in people with chronic obstructive pulmonary disease. J Pain Sympt Manag 2006;32:60-70.

52. Kunik ME, Veazey C, Cully JA, et al. COPD education and cognitive behavioral therapy group treatment for clinically significant symptoms of depression and anxiety in COPD patients: A randomized controlled trial. Psychol Med 2008;38:385-96.

53. Lomundal BK, Steinsbekk A. Observational studies of a one year self-management program and a two year pulmonary rehabilitation program in patients with COPD. Int J COPD 2007;2:617-24.

54. Niesink A, Trappenburg JCA, de Weert-van Oene GH, Lammers JW, Verheij TJ, Schrijvers FP. Systematic review of the effects of chronic disease management on quality of life in people with chronic obstructive pulmonary disease. Resp Med 2007;101:2233-99.

55. Louie SW. The effects of guided imagery relaxation in people with COPD. Occup Ther Int 2004;11:145-59.

56. Engen RL. The singer's breath: Implications for treatment of persons with emphysema. J Music Ther 2005;42:20-48.

57. Giardino ND, Chan L, Borson S. Combined heart rate variability and pulse oximetry biofeedback for chronic obstructive pulmonary disease: Preliminary findings. Appl Psychophysiol 2004;29:121-33.

58. Ketelaars CAJ, Abu-Saad HH, Haifens RJG, Schlosser MAG, Mostert R, Wouters EFM. Effects of specialized community nursing care in patients with chronic obstructive pulmonary disease. Heart Lung. J Acute Crit Care 1998;27:109-20.

59. Wu HS, Li-Chan L, Wu SC, Lin JG. The psychologic consequences of chronic dyspnea in chronic obstructive pulmonary disease: The effects of acupressure on depression. J Alt Compl Med 2007;13:253-61

60. Wu HS, Wu SC, Lon JG, Lin LC. Effectiveness of acupressure in improving dyspnoea in chronic obstructive pulmonary disease. J Adv Nurs 2004:45:307-10.

61. Maa SH, Gauthier D, Turner M. Acupressure as an adjunct to a pulmonary rehabilitation program. J Cardiopulm Rehab 1997;17:268-76.

62. Bauldoff GS, Hoffman LA, Zullo TG, Sciurba FC. Exercise maintenance following pulmonary rehabilitation. Chest 2002;122:948-54.

63. Bauldoff GS, Rittinger M, Nelson T, Doehrel J, Diaz PT. Feasibility of distractive auditory stimuli on upper extremity training in persons with chronic obstructive pulmonary disease. J Cardiopulm Rehab 2005;25:50-5.

64. Brooks D, Sidani S, Graydon J, McBride S, Hall S, Weihnacht K. Evaluating the effects of music on dyspnea during exercise in individuals with chronic obstructive pulmonary disease: A pilot study. Rehab Nursing 2003;28:192-6.

65. Pfister T, Berrol C, Caplan C. Effect of music on exercise and perceived symptoms in patients with chronic obstructive pulmonary disease. J Cardiopulm Rehab 1998;18:228-32.
66. Sidani S, Brooks D, Graydon J, Hall L. Evaluating the effects of music on dyspnea and anxiety in patients with COPD: A process-outcome analysis. Int Nurs Persp 2004:4:5-13.

67. Crisafulli E, Costi S, De Balsio F, et al. Effect of a walking aid in COPD patients receiving oxygen therapy. Chest 2007;131:1068-74.

68. Gupta R, Goldstein R, Brooks D. The acute effects of a rollator in individuals with COPD. J Cardiopulm Rehab 2006;26:107-11.

69. Gupta R, Brooks D, Lacasse Y, Goldstein R. Effect of rollator use on health-related quality of life in individuals with COPD. Chest 2006;130:1089-95.

70. Honeyman P, Barr P, Stubbing DG. Effect of a walking aid on disability, oxygenation and breathlessness in patients with chronic airflow obstruction. J Cardiopulm Rehab 1996;16:63-7.

71. Probst VS, Troosters T, Coosemans I, et al. Mechanisms of improvement in exercise capacity using a rollator in patients with COPD. Chest 2004;126:1102-7.

72. Solway S, Brooks D, Lau L, Goldstein R. The short-term effect of a rollator on functional exercise capacity among individuals with severe COPD. Chest 2002;122:56-65.

73. Nakayama H, Shibuya M, Yamada M, Suzuki H, Arakawa M, Homma I. In-phase chest wall vibration decreases dyspnea during arm elevation in chronic obstructive pulmonary disease patients. Intern Med 1998;37:831-5.

74. Bourjeily-Habr G, Rochester CL, Palermo F, Snyder P, Mohsenin V. Randomised controlled trial of transcutaneous electrical muscle stimulation of the lower extremities in patients with chronic obstructive pulmonary disease. Thorax 2002;57:1045-9.

75. Neder JA, Sword D, Ward SA, Mackay E, Cochrane LA, Clark CJ. Home based neuromuscular electrical stimulation as a new rehabilitative strategy for severely disabled patients with chronic obstructive pulmonary disease (COPD). Thorax 2002;57:333-7.

76. Vivodtzev I, Pepin JL, Voltero G, et al. Improvement in quadriceps strength and dyspnea in severely deconditioned and malnourished COPD. Chest 2006;129:1540-9.

77. Baltzan MA, Alter A, Rotaple M, Kamel H, Wolkove N. Fan to palliate exercise-induced dyspnoea with severe COPD. Am J Resp Crit Care Med 2000;161(3 Suppl):A59.

78. Rea H, McAuley S, Stewart A, Lamont C, Roseman P, Didsbury P. A chronic disease management programme can reduce days in hospital for patients with chronic pulmonary disease. Int Med J 2004;34:608-14.

79. Wu X, Hou L, Bai W. Effects of breathing training on quality of life and activities of daily living in elderly patients with stable severe COPD. Chin J Rehab Med 2006;21:307-10.

80. Hermiz O, Comino E, Marks G, Daffurn K, Wilson S, Harris M. Randomised controlled trial of home based care of patients with chronic obstructive pulmonary disease. Br Med J 2002;325:938-43.

81. Egan E, Clavariono A, Burridge L, Teuwen M, White E. A randomized controlled trial of nursing based case management with chronic obstructive pulmonary disease. Lippincott's Case Management 2002;7:170-9.

82. Eiser N, West C, Evans S, Jeffers A, Quirk F. Effects of psychotherapy in moderately severe COPD: A pilot study. Eur Resp J 1997;10:1581-4.

83. Nocturnal Oxygen Therapy Trial Group. Continuous or nocturnal oxygen therapy in chronic obstructive pulmonary disease. Ann Intern Med 1980;93:391-8.

84. Medical Research Council Working Party. Long term domiciliary oxygen therapy in chronic hypoxic cor pulmonale complicating chronic bronchitis and emphysema. Lancet 1981;1:681-6.

85. Górecka D, Gorzelak K, Sliwinski P, Tobiasz M, Zielinski J. Effects of long term oxygen therapy on survival in patients with chronic obstructive pulmonary disease with moderate hypoxemia Thorax 1997;52:674-9.

86. Bradley JM, Lasserson T, Elborn S, MacMahon J, O'Neill B. A systematic review of randomized controlled trials examining the short term benefit of ambulatory oxygen in COPD. Chest 2007;131:278-85.

87. Booth S, Wade R, Johnson M, Kite S, Swannick M, Anderson H. The use of oxygen in the palliation of breathlessness. Respir Med 2004:98:66-77.

88. O'Donnell DE, D'Arsigny C, Webb KA. Effects of hyperoxia on ventilatory limitation during exercise in advanced chronic obstructive pulmonary disease. Am J Respir Crit Care Med 2001;163:892-8. 
89. Snider GL. Enhancements of exercise performance in COPD patients by hyperoxia. Chest 2002;122:1830-6.

90. Swinburn CR, Mould H, Stone TN, Corris PA, Gibson GJ. Symptomatic benefit of supplemental oxygen in hypoxemic patients with chronic lung disease. Am Rev Respir Dis 1991;143:913-5.

91. Alvisi V, Romanello A, Badet M, Gaillard S, Philit F, Guérin C. Time course of expiratory flow limitation in COPD patients during acute respiratory failure requiring mechanical ventilation. Chest 2003;123:1625-32.

92. Liss HP, Grant BJ. The effect of nasal flow on breathlessness in patients with chronic obstructive pulmonary disease. Am Rev Respir Dis 1988;137:1285-8.

93. Lilker ES, Karnick A, Lerner L. Portable oxygen in chronic obstructive lung disease with hypoxemia and cor pulmonale. Chest 1975;68:236-41.

94. Heaton RK, Grant I, McSweeny, Adams KM, Petty TL. Psychological effects of continuous and nocturnal oxygen therapy in hypoxemic chronic obstructive pulmonary disease. Arch Intern Med 1983;143:1941-7.

95. Okubadejo AA, Paul EA, Jones P, Wedzicha JA. Does long term oxygen therapy affect quality of life in patients with chronic obstructive pulmonary disease and severe hypoxemia? Eur Respir J 1996;9:2335-9.

96. Eaton T, Lewis C, Young P, Kennedy Y, Garrett JE, Kolbe J. Long term oxygen therapy improves health-related quality of life. Respir Med 2004;98:285-93.

97. Lahdensuo A, Ojanen M, Ahonen A, et al. Psychological effects of continuous oxygen therapy in hypoxaemic chronic obstructive pulmonary disease. Eur Respir J 1989;2:977-80.

98. Crockett AJ, Cranston JM, Moss JR, Alpers JH. Effects of long-term oxygen therapy on quality of life and survival in chronic airflow limitation. Monaldi Arch Chest Dis 1999;54:193-6.

99. McDonald CF, Blyth CM, Lazarus MD, Marschner I, Barter CE. Exertional oxygen of limited benefit in patients with chronic obstructive pulmonary disease and mild hypoxemia. Am J Respir Crit Care Med 1995;152:1616-9.

100. Eaton T, Garrett JE, Young P, et al. Ambulatory oxygen improves quality of life of COPD patients: A randomized controlled study. Eur Respir J 2002;20:306-12.

101. Nonoyama ML, Brooks D, Guyatt G, Goldstein RS. Effect of oxygen on health quality of life in patients with chronic obstructive pulmonary disease with transient exertional hypoxemia. Am J Respir Crit Care Med 2007;176:343-9.

102. Moore RP, Berlowitz DJ, Denehy L, et al. A randomized trial of domiciliary, ambulatory oxygen in patients with COPD and dyspnea but without resting hypoxemia. Thorax 2011;66:32-7.
103. Lacasse Y, Lecours R, Pelletier C, Begin R, Maltais F. Randomized trial of ambulatory oxygen in oxygen-dependent COPD. Eur Respir J 2005;25:1032-8.

104. Sandland CJ, Morgan MDL, Singh SJ. Patterns of domestic activity and ambulatory oxygen usage in COPD. Chest 2008;134:753-60.

105. Abernathy A, McDonald C, Frith PA, et al. Effect of palliative oxygen versus room air in relief of breathlessness in patients with refractory dyspnoea: A double-blind, randomized controlled trial. Lancet 2010;376:784-93.

106. Mularski RA, Campbell ML, Asch SM, et al. A review of quality of care evaluation for the palliation of dyspnea. Am J Respir Crit Care Med 2010;181:534-8.

107. Bausewein C, Farquhar M, Booth S, Gysels M, Higginson IJ. Measurement of breathlessness in advanced disease: A systematic review. Respir Med 2007;101:399-410.

108. Dorman S, Byrne A, Edwards A. Which measurement scales should we use to measure breathlessness in palliative care? A systematic review. Palliat Med 2007;21:177-91

109. O'Donnell DE, Aaron S, Bourbeau J, et al. Canadian Thoracic Society recommendations for management of chronic obstructive pulmonary disease - 2007 update. Can Respir J 2007;14(Suppl B):5B-32B.

110. O'Donnell DE, Hernandez P, Kaplan A, et al. Canadian Thoracic Society recommendations for management of chronic obstructive pulmonary disease -2008 update - highlights for primary care. Can Respir J 2008;15(Suppl A):1A-8A.

111. Celli BR, MacNee W. Standards for the diagnosis and treatment of patients with COPD: A summary of the ATS/ERS position paper. Eur Respir J 2004;23:932-46.

112. American Thoracic Society. Dyspnea. Mechanisms, assessment, and management: A consensus statement. Am J Respir Crit Care Med 1999;159:321-40.

113. Rabe KF, Hurd S, Anzueto A, et al; Global Initiative for Chronic Obstructive Lung Disease. Global strategy for the diagnosis, management, and prevention of chronic obstructive pulmonary disease: GOLD executive summary. Am J Respir Crit Care Med 2007;176:532-55.

114. Abramson MJ, Crockett AJ, Frith PA, McDonald CF. COPDX: An update of guidelines for the management of chronic obstructive pulmonary disease with a review of recent evidence. Med J Aust 2006; $184: 342-5$.

115. Rocker G, Sinuff T, Horton R, Hernandez P. Advanced chronic obstructive pulmonary disease: Innovative approaches to palliation. J Palliat Med 2007;10:783-97. 


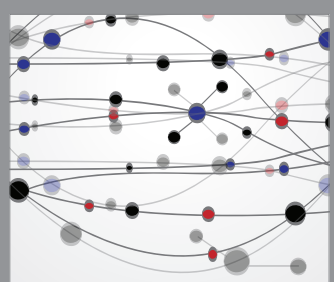

The Scientific World Journal
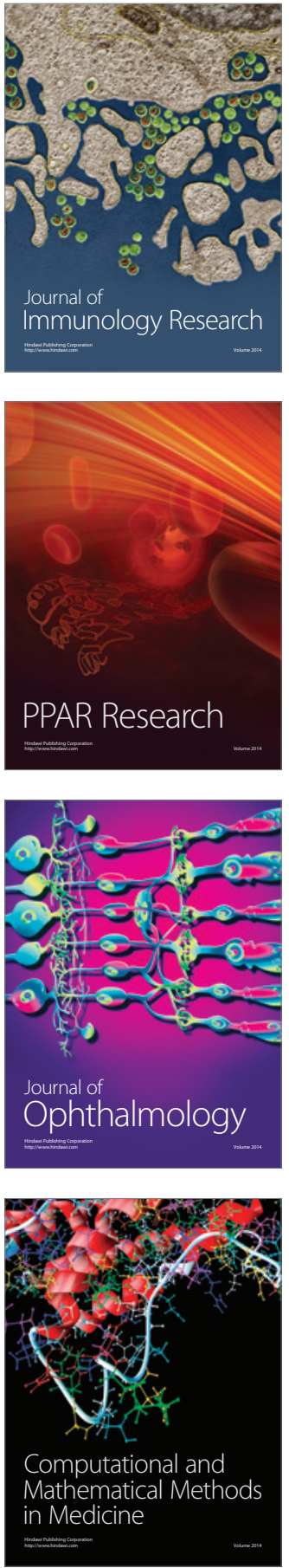

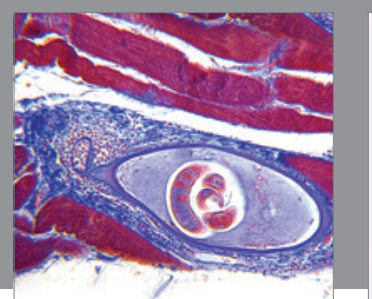

Gastroenterology Research and Practice

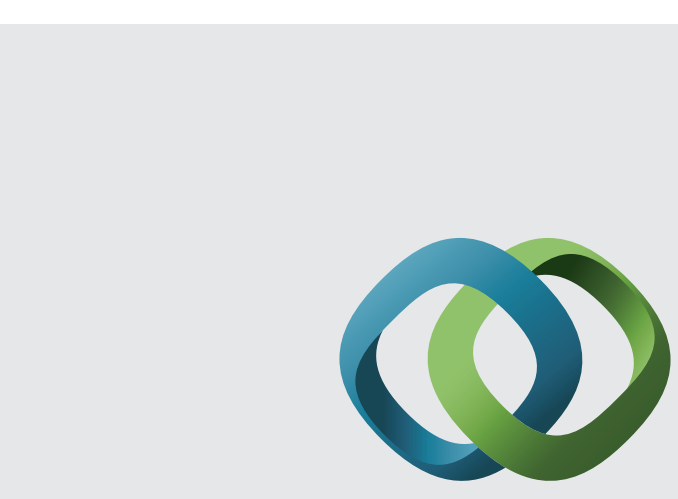

\section{Hindawi}

Submit your manuscripts at

http://www.hindawi.com
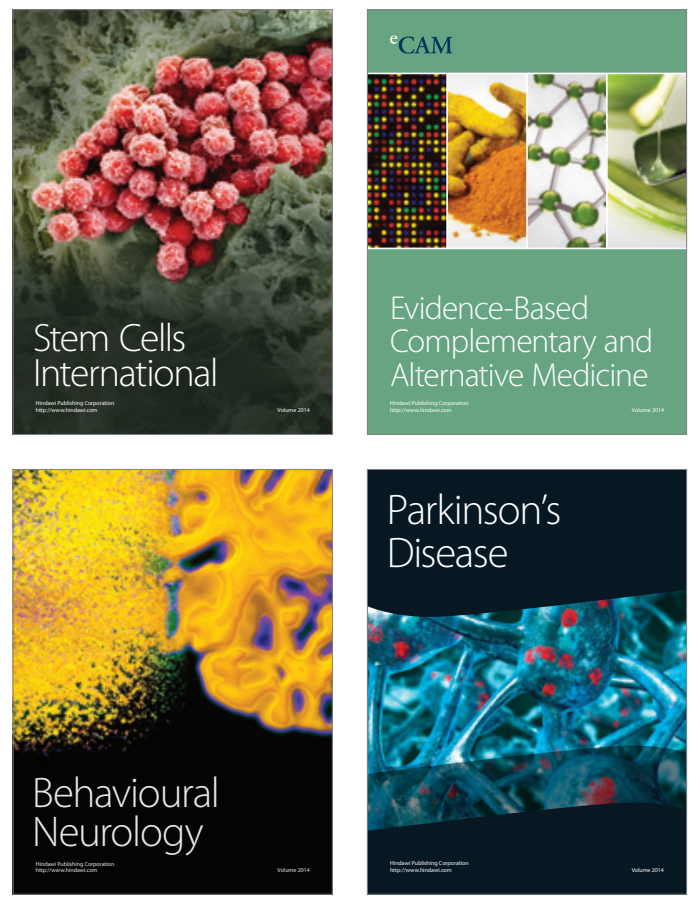
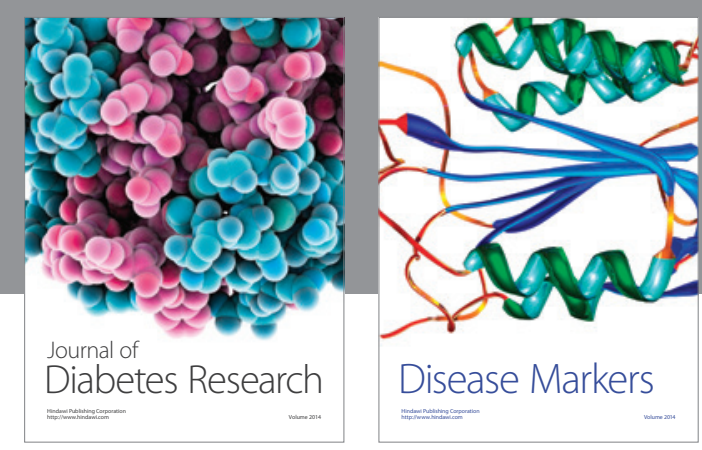

Disease Markers
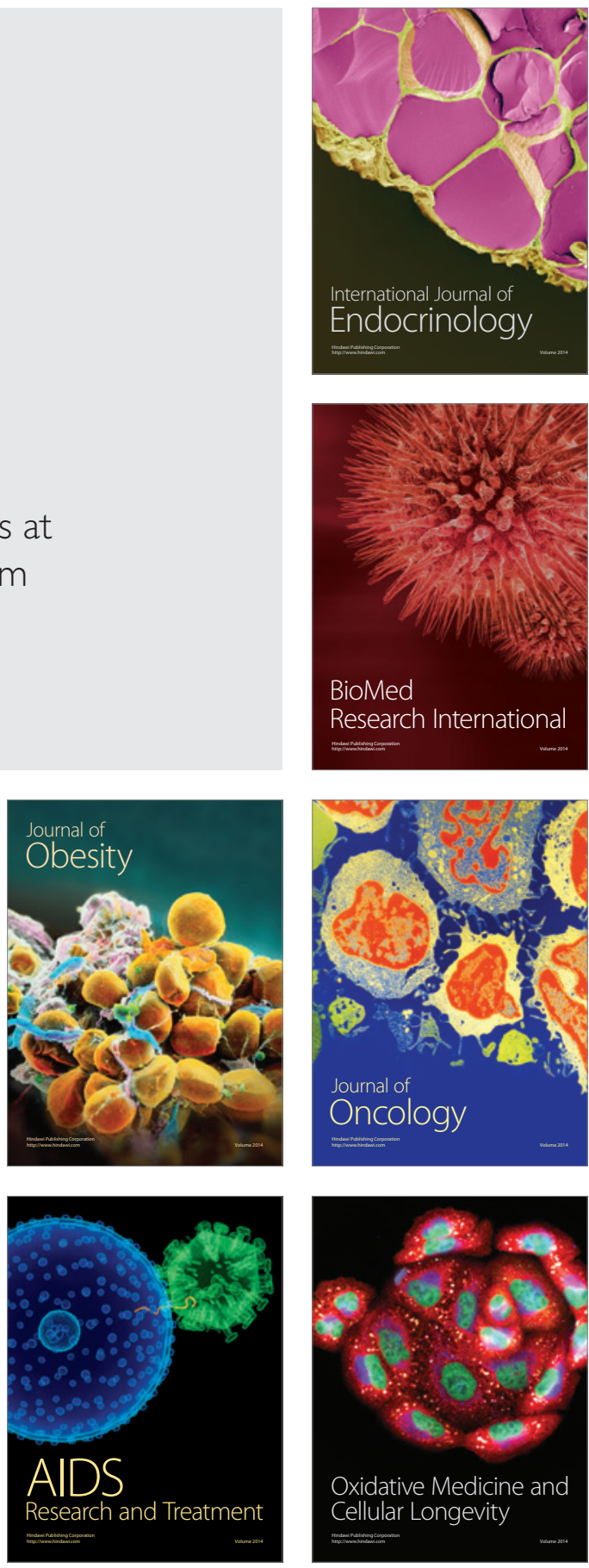